\title{
The challenges of knowledge management portals application and implementation: An Iranian organizations case study
}

\author{
Payman Akhavan $^{\text {1a }}$, Mohammad Saleh Adalati ${ }^{\mathrm{a}}$, Sara Sharifi-Yazdi ${ }^{\mathrm{b}}$ and Reza Hosnavi $^{\mathrm{a}}$ \\ ${ }^{a}$ Department of Industrial Engineering, Iran University of Science and Technology, Tehran Iran \\ ${ }^{b}$ Department of Social Science, University of Tehran, Tehran, Iran

ARTICLEINFO ABSTRACT \\ Article history: \\ Received 1 January 2010 \\ Received in revised form \\ 28 March 2010 \\ Accepted 1 April 2010 \\ Available online 7 April 2010 \\ Keywords: \\ Knowledge management, \\ portal challenges, \\ information technology, \\ factor analysis

\begin{abstract}
This article aims to review, identify and prioritize challenge factors of the implementation of the weakness in organizational strategy, information overcrowd, content management, portals where managerial factors are in the highest priority and financial factors are in the lowest Financial and information security, Technology and management, Senior management support organizations and it is hard to gather information from limited number of organizations or for knowledge management planners and managers in organizations and clear the prospects to
\end{abstract} \\ knowledge management portals for Iranian organizations. The study determines several \\ important weakness factors affecting the implications of the knowledge management such as \\ project management, and etc. The study also indicates that the factors have different priorities \\ priority. We also perform factor analysis to summarize seventeen factors into six issues: \\ and strategy, Acceptance, User's motivation and culture, Project management, Change \\ management and training. Knowledge management portal is a brand new concept for Iranian \\ companies for applied knowledge management portals. The results of this study could be useful \\ deal with the challenges.
}

(C) 2010 Growing Science Ltd. All rights reserved.

\section{Introduction:}

During the past few years, knowledge management (KM) has become an important subject of study (Akhavan et al., 2006) among practitioners in the field of management, industrial engineering, and information technology. KM fundamentally gains insight into the topic of intellectual capital management (Jafari et al., 2009) to create a company with competitive advantage. Although KM requires information technology but it cannot be simply acquired through a complete software package. Successful implementation of KM needs long-term commitment from senior managers who are dedicated to train employees and managers (Bergeron, 2003). Nevertheless, Information technology (IT) tools play an important role in developing KM for many Iranian industries. Among various types of IT tools, portals are the most effective ways of sharing knowledge and information in organizations. They act as nervous systems for a company which could support the business processes and the flow of information (Kim, 2003). However, it is clear that every plan is not risk-free and there are challenges especially at the beginning stages of its development (Akhavan et al., 2006). In fact, any

1 Corresponding author Fax:+982177240482. Email: akhavan@iust.ac.ir (P. Akhavan)

(c) 2010 Growing Science Ltd. All rights reserved. doi: 10.5267/j.ijiec.2010.01.008 
implementation of KM portal could fail if all risk factors are not carefully determined. The primary objective of this research is to identify potential challenges of the implementation of KM portals. We also study different challenging factors of the implementation of KM Iranian industries and determine the most important ones based on some statistical tests.

\section{Knowledge management and its process}

Knowledge Management is the strategic efforts of organizations (Jafari et al., 2007) to gain a competitive advantage and using intellectual assets and resources which exist in employees and clients (Encyclopedia of Management, 1999). Nonaka and Takeuchi (1995) developed knowledge conversion model which helps to understand how the processes of transferring and creating knowledge are intimately connected. They believe the best way of knowledge creation in organizations is a simple process to amplify the creation of knowledge with individuals and adds its results to the knowledge network of the organization. In their model, the basis of knowledge creation in organizations is successive interaction (transfer) among individuals, and successive conversion from tacit knowledge into explicit knowledge (and vice-versa) by individuals. The model recognizes four modes of knowledge conversion:

Socialization; is the exchange of tacit knowledge to tacit knowledge through the intermediate shares of the experiences inside the organization.

Externalization; is the process of articulating tacit knowledge and transforming it into explicit knowledge as models, concepts, analogies, stories and metaphors. Externalization is considered as a key phase in the knowledge creation and is induced by dialog, collective reflection, writing. Writing the knowledge is an example of the effort normally required by externalization projects.

Combination; is the process of combining bodies of explicit knowledge in order to create new explicit knowledge which is the most common process in formal education systems. In many organizations, it is created by the conversion of explicit knowledge among members, as in formal reunions.

Internalization; is the process of adding explicit knowledge to new tacit knowledge in the forms of sensations, memories and images through experimenting different methods, as through real life experience, simulation of limit situations through the usage of software. The knowledge conversion process has been represented by Nonaka and Takeuchi (1995).

\section{The role of information technology (IT) in knowledge management}

Davenport et al. (1998) Considered basic components of knowledge management which include culture, process operation, policies and technology. There are normally two dimensions associated with any KM. The first dimension includes technologies and communication technologies and information, and the other one includes social systems and human resource of organizations. In fact, KM gets benefit from an interaction between communication and information technologies using social systems. The role of IT in KM is a vital aspect for any organization which intends to use the technologies for managing their knowledge. IT can provide knowledge from the mass of information stored in all parts of the organizations. In fact, conversion process of information and knowledge happens through IT which represents the external power of understanding, learning and gathering the necessary information. IT has made it easier to acquire, store, or disseminate knowledge than ever before and many organizations are employing IT to facilitate sharing and integration of knowledge. If properly used, IT can also accelerate knowledge-sharing capabilities in both time and space dimensions. Locality, timing, and relevancy factors determine the expediency and the strength of IT's role in KM initiatives. On the other hand, due to the difficulty of incorporating most of human behavior aspects in technology, IT cannot fully put into operation many of KM's humanistic features. Therefore, IT cannot be considered the magic bullet which makes a KM initiative a complete success. Hence, IT has to be part of a balanced and integrated set of components. Too much emphasis on technology without incorporating the other critical elements could easily result in a failure of a system. Furthermore, codifying knowledge with the power of the existing IT and without the support from socio-cultural inputs will result in decontextualization, i.e. "knowledge dilution". IT must be accompanied by social networks such as communities of practice and other human interventions to create the requisite synergistic effects.

In summary, technology is a necessity tool for handling KM (Jafari and Akhavan, 2007). IT tools are used to capture, codify, store and distribute knowledge throughout the organization. IT tools such as Internet, Intranet, Extranet, Email, Electronic Data Management Systems (EDMS), Decision Support Systems, Expert Systems, Groupware, Wikis, Weblogs, and other shared networked and net-based technologies are used to leverage KM processes in the organization. IT provides to the members in an organization, the platform to communicate and 
to get access to the right information at the right time for the right purpose. Therefore, there must be a balance between knowledge management initiatives and engagement of IT tools and infrastructure in order to exploit the benefits of KM to the fullest. By focusing on IT as the most integral component of KM, may jeopardize the potential benefit from KM activities and may lead to failure in KM implementation. Vaccaro et al. (2009) identifies all the ICT tools which are useful in knowledge management and categorize them by their applications in knowledge management processes.

Table1

Knowledge and ICT related tools

\section{Prevalent mode ICT application}

Socialization Virtual design tools (e.g. 2D/3D-Cad, structural-design-software, design software for electricity component, internet-based messengers

Externalization Word editor

Combination

Email, Internet, Virtual communities, Project database, emails, corporate databases, text editor

Internalization

Corporate databases, Virtual design tools, structural design software, design software for electricity, Workflow systems

Source: Vaccaro et al. (2009)

\section{Types of knowledge management technologies}

Carvalho and Ferreira (2001) classified different aspects of knowledge management technologies regarding to their role in the knowledge conversion process as follows:

Table2.

Knowledge transfer processes and ICT related tools

\begin{tabular}{lll}
\hline & To Tacit & To Explicit \\
\cline { 2 - 3 } From Tacit & Socialization & Externalization \\
& Knowledge Maps & Groupware \\
& Knowledge Portals & Workflow \\
& & Knowledge-Based Systems \\
& Internalization & Knowledge Portals \\
\hline From Explicit & Innovation Support Tools & Combination \\
& & Intranet \\
& & Electronic Document Management \\
& & Business Intelligence \\
& & Competitive Intelligence \\
& & Knowledge Portals \\
\hline
\end{tabular}

Source: Carvalho and Ferreira (2001)

As we can observe from Table 2, Knowledge portals are important tools for the many knowledge transfer processes. In addition to IT development, portals can also include other IT tools such as Email, Electronic Data Management Systems (EDMS), Decision Support Systems, Expert Systems, Groupware, Wikis, Weblogs, and other shared networked and net-based technologies which are used to leverage KM processes through the organizations.

\section{Knowledge management portals}


In an effort to make departmental portals more strong and stable, they are enhanced with more capabilities such as departmental intranet and extranet internet sources. Nowadays, portals are known as the most effective ways for sharing information and knowledge in organizations. They act as nervous system for companies and support business processes and information flow (Kim 2003). Blackmore (1997) describes portals as an instrument to benefit from internet technologies in an organizational computerized environment. Portals are web based and they provide access to the information and applications through web pages. In other words, portals are web pages which do not provide any kind of services by themselves and they only guide the users simply to the sites and information they need. Firestone (2003) classifies portals in three sets,

- $\quad$ "Business portals,

- Corporate portals - collaborative portals tying together peers, collaborative portals tying together skills and information needs,

- Enterprise information portals—decision processing portals, collaborative portals, and knowledge portals."

Knowledge portals are tools to extract classified analysis for both unstructured and structured information and these portals clarify the relation among content, human, subjects and users activations. They can also provide variety of services such as chat room, email, research motors, customized news, RSS feedback, and external links (Jain 2009). Mphidi and Snyman (2004) study the portals and report different benefits such as compatibility, interaction, easy updated and low cost, user friendly interaction, focus, etc.

\section{Challenges of knowledge management portals}

Jennex (2007) studied different critical success factors in KM and reported that portals are an important component of a knowledge management system. Ackerman (1994) developed a system called "Answer Garden (AG)" which is a system designed to grow organizational memory in the context of help-desk situations. The AG was implemented on six organizations and the results indicated that only one organization could successfully use it mainly because the expectations of the capabilities of the system exceeded the actual capabilities. Ackerman and Mandel (1996) reported that a smaller task-based system was more effective on the sub-organization level because of its narrower expectations. Mandviwalla, et al. (1998) in their research described several strategy issues affecting the design process of a KM system (KMS). These issues include the focus of the KMS on the users, and the amount of knowledge to be captured and in what formats; who must filters what should be captured, and what reliance and/or limitations should be placed on the use of individual memories. Additional technical issues affecting KMS design process include knowledge storage/repository considerations, how information and knowledge should be organized so that it can be searched and linked to appropriate events and use, and processes for integrating the various repositories and for re-integrating information and knowledge extracted from specific events. Some management issues include how long the knowledge is useful for KMS, access locations as users rarely access the KMS from a single location, and the work activities and processes that utilize the KMS .

Davenport, et al. (1998) studied in 24 companies and their 31 projects. Eighteen projects were determined to be successful, five were determined as failures, and eight were new started to be rated. They found eight factors as the important issues in the success of KM projects as follows,

- Senior management support

- Clearly communicated KMS purpose/goals

- Linkages to economic performance

- Multiple channels for knowledge transfer

- Motivational incentives for KM users

- A knowledge friendly culture

- A solid technical and organizational infrastructure

- A standard, flexible knowledge structure.

Sage and Rouse (1999) performed a survey on the history of innovation and technology and identified the following issues :

- Modeling processes to identify the knowledge needs and the sources

- KMS strategy for the identification of knowledge to capture and use

- Providing incentives and motivation to use the KMS 
- Infrastructure for capturing, searching, retrieving, and displaying knowledge

- An understood enterprise knowledge structure

- Clear goals for the KMS

- Measuring and evaluating the effectiveness of the KMS

Ginsberg and Kambil (1999) investigated different issues in designing and implementing of an efficient KMS by building a KMS based on various issues identified in the literature. They found knowledge storage, representation, retrieval, search, visualization, and quality control as the most important technical issues of KMS. Alavi and Leidner (1999) investigated executive participants in an executive development program with respect to what was needed for a successful KMS. They found organizational and cultural issues associated with user motivation to share to be the most significant. They also found it important to measure the benefits of the KMS and to have an integrated and integrative technology architecture which supports database, communication, and search and retrieval functions . Cross and Baird (2000) in their investigation reported that KM would not improve business performance simply by using technology to capture and share the lessons of experience. In their survey, they claimed that the creation of organizational memory could improve the business performance and indicated some of the most important parameters on the success of KM as follows,

- Supporting personal relationships between experts and knowledge users

- Providing incentives to motivate users to learn from experience and to use the KMS

- Providing distributed databases to store knowledge and pointers to knowledge

- Providing work processes for users to convert personal experience into organizational learning

- Providing direction to what knowledge the organization needs to capture and learn from .

Holsapple and Joshi (2000) investigated factors that influenced the management of knowledge in organizations through the use of a Delphi panel consisting of 31 recognized KM researchers and practitioners. They found leadership and top management commitment/support to be crucial. Resource influences such as having sufficient financial support, skill level of employees, and identified knowledge sources are also important . Koskinen (2001) investigated tacit knowledge as a promoter of success in technology firms by studying ten small technology firms. Key to the success of a KMS was the ability to identify, capture, and transfer critical tacit knowledge. A significant finding was that new members take a long time to learn critical tacit knowledge and a good KMS facilitates the transference of this tacit knowledge to new members. Jennex and Olfman (2000) studied three KM projects to identify design recommendations for building a successful KMS. These recommendations include :

- Develop a good technical infrastructure by using a common network structure, adding KM skills to the technology support skill set, using high end PCs; integrated databases; and standardizing hardware and software across the organization

- Incorporate the KMS into everyday processes and information system by automating knowledge capture

- Have a wide enterprise knowledge structure

- Have Senior Management support

- Allocate maintenance resources for OMS

- Train users on use and content of the OMS

- Create and implement a KM Strategy/Process for identifying/maintaining the knowledge base

- Expand system models/life cycles to include the KMS and assess system/process changes for impact on the KMS

- Design security into the KMS

- Build motivation and commitment by incorporating KMS usage into personnel evaluation processes; implementing KMS use/satisfaction metrics; and identifying organizational culture concerns that could inhibit KMS usage.

Jennex and Olfman (2002) performed a longitudinal study of KM on one of these organizations and found that new members of an organization do not use the computerized KMS due to a lack of context for understanding the knowledge and the KMS. They found that these users needed pointers to knowledge more than codified knowledge. Jennex et al. (2003) investigated the requirements for having an organizational KM strategy to ensure that knowledge benefits gained from projects which are captured to use in the organization by surveying Year 2000 project leaders. They found that benefits from year 2000 projects were not being captured because the parent organizations did not have a KM strategy/process. Their conclusion was that KM in projects 
can exist and can assist projects in utilizing knowledge during the project. Malhotra and Galletta (2003) identified the critical importance of user commitment and motivation through a survey study of users about KMS being implemented in a health care organization. They found that using incentives did not guarantee a successful KMS. They created an instrument for measuring user commitment and motivation that is similar to Thompson et al. (1991) Perceived Benefit model but based on self-determination theory that uses the Perceived Locus of Causality. Barna (2003) studied six KM projects with various levels of success where three were successful, two failed, and one was an initial failure turned into a success and identified two groups of factors important to a successful KMS. The main managerial success factor is creating and promoting a culture of knowledge sharing within the organization by articulating a corporate KM vision, rewarding employees for knowledge sharing, creating communities of practice, and creating of a "best practices" repository. Other managerial success factors include obtaining senior management support, creating a learning organization, providing KMS training, and precisely defining KMS project objectives. Design/construction success factors include approaching the problem as an organizational problem and not a technical one, creating a standard knowledge submission process, methodologies and processes for the codification, documentation, and storage of knowledge, processes for capturing and converting individual tacit knowledge into organizational knowledge. Also create relevant and easily accessible knowledge-sharing databases and knowledge maps. In Brian Bergeron's (2003) opinion the most important challenges in effective use of knowledge management technology is the consistency and integrity. For example, decision support tools must be identified and clarified within the work process in order to improve the work process. A successful Knowledge Management System (KMS) should perform the functions of knowledge creation, storage/retrieval, transfer, and application very well. However, some other factors can affect KMS success as well. Yu, et al. (2004) explored the linkage of organizational culture to knowledge management success. They found that KM drivers such as a learning culture, knowledge sharing intention, KMS quality, rewards, and KM team activity significantly affected KM performance. These conclusions were reached through a survey of 66 Korean firms. Uden and Naaranoja (2007) identified organizational barriers to knowledge management portals as follows:

- Senior management culture and support: Where is the return on investment?

- Identifying the knowledge base: Who really knows about this?

- Buy in from knowledge workers and employees: What's in it for me?

- Management and distribution of relevant and accurate content: Does this really work?

Okujava and Remus (2007) in their research determined six risk factors as the most important issues which could affect the success of KMS which are summarized in Table 3.

Table3.

Risk factors of portals

Risks Examples

General project risks

Vague objectives, Improper project scope definition, False interpretation of customer (end user) needs

Personnel risks

Insufficient project management

Financial risks

Low budget, Budget cutting

Deadline risks

Failure to meet deadlines

Acceptance risks

Risk of low acceptance rate by customers or end users

Technology risks

Compatibility problems, Problems with legacy systems, Interface problems

Source: Okujava (2007)

Landqvist and Stenmark (2007) detected that the portal itself would be the most important challenge from an information management prospective and classified three set of challenges for portals. First, without actual users it is difficult for developers to correctly identify how knowledge is being utilized across the organization. Second, portals span the entire organization and must be based on the input from all stakeholders. Third, a portal changes the routines of the organization. To ensure the buy-in from as many users as possible, they need to be involved earlier in the development process. In Ulrich Remus (2007) view, portals critical success factors are classified in two groups which are organizational and Technological described as follows, 
Organizational: Top management support, Dedicated resources, Organizational culture, Team competencies and skills, Business process reengineering, Change management, User acceptance, Clear goals and objectives, Flexible project structure, Project management, Project monitoring and controlling, Strong communication inwards \& outwards, User training and education

Technological: Defining the portal architecture, Requirements analysis, Process and application integration, Prototyping, Portal design, Selection of the appropriate portal package, Portal strategy Portal engineering roadmap

Hahn and Wang (2009) identified four group challenges of complexity, uncertainty, ambiguity and equivocality on knowledge processes. A comprehensive survey of all existing issues affecting $\mathrm{KM}$ is summarized in Table 4.

Table4

The challenges of knowledge management portals

\begin{tabular}{|c|c|c|}
\hline No & Challenge Factor & References \\
\hline 1 & $\begin{array}{l}\text { Organizational } \\
\text { weakness }\end{array}$ & $\begin{array}{l}\text { Remus(2007), Barna(2003), Ginsberg and Kambil (1999),Holsapple and } \\
\text { joshi(2000), jennex(2003),Koskinen (2001), Mandviwalla et al.(1998), Sage and } \\
\text { Rose (1999), Yu et al(2004), Jennex et al. (2003) }\end{array}$ \\
\hline 2 & $\begin{array}{l}\text { Information overcrowd and } \\
\text { content management } \\
\text { weakness }\end{array}$ & Uden and Naaranoja (2007), Landqvist and Stenmark (2007) \\
\hline 3 & $\begin{array}{l}\text { Portals project } \\
\text { management weakness }\end{array}$ & Remus (2007), Okujava and Remus (2007) \\
\hline 4 & Weakness in training & $\begin{array}{l}\text { Uden and Naaranoja (2007), Remus (2007), Okujava and Remus (2007), Holsapple } \\
\text { and Joshi (2000), Barna (2003) }\end{array}$ \\
\hline 5 & $\begin{array}{lr}\text { Low } & \text { technology } \\
\text { acceptance } & \text { among } \\
\text { employees } & \end{array}$ & Uden and Naaranoja (2007), Remus (2007), Okujava and Remus (2007) \\
\hline 6 & $\begin{array}{l}\text { Financial and budget } \\
\text { problems }\end{array}$ & Okujava and Remus (2007), Holsapple and Joshi (2000) \\
\hline 7 & Weak acceptance of portal & Remus (2007), Okujava and Remus (2007), Landqvist and Stenmark (2007) \\
\hline 8 & $\begin{array}{l}\text { Motivation weakness } \\
\text { among portal's users and } \\
\text { stakeholders }\end{array}$ & $\begin{array}{l}\text { Landqvist and Stenmark (2007), Alavi and leidner (1999), Davenport et al. (1998), } \\
\text { Jennex and Olfman (2000), Malhotra and Galletta (2003), Barna (2003) }\end{array}$ \\
\hline 9 & $\begin{array}{l}\text { Lack of flexibility and } \\
\text { weakness in change } \\
\text { management }\end{array}$ & Remus (2007), Landqvist and Stenmark (2007) \\
\hline 10 & $\begin{array}{l}\text { Lack of cohesion between } \\
\text { portal and organization } \\
\text { structure }\end{array}$ & $\begin{array}{l}\text { Remus (2007), Bergeron (2003), akerman (1994), Barna (2003), Cross and Baird } \\
\text { (2000), Davenport et al. (1998), Ginsberg and Kambil (1999), Jennex and Olfman } \\
\text { (2000), Mandviwalla et al. (1998), Sage and Rose (1999) }\end{array}$ \\
\hline 11 & $\begin{array}{l}\text { Lack of senior manager's } \\
\text { commitment and support }\end{array}$ & $\begin{array}{l}\text { Remus (2007), Uden and Naaranoja (2007), Davenport et al. (1998), Jennex and } \\
\text { Olfman (2000), Sage and Rose (1999), Yu, et al. (2004), Holsapple and Joshi (2000), } \\
\text { Barna (2003) }\end{array}$ \\
\hline 12 & $\begin{array}{l}\text { Weakness in knowledge } \\
\text { sharing culture }\end{array}$ & $\begin{array}{l}\text { Remus (2007), Alavi and Leidner (1999), Davenport et al. (1998), Jennex and } \\
\text { Olfman (2000), Sage and Rose (1999), Yu, et al. (2004), Barna (2003) }\end{array}$ \\
\hline 13 & $\begin{array}{l}\text { Weaknesses in economic } \\
\text { efficiency }\end{array}$ & Okujava and Remus (2007) \\
\hline 14 & $\begin{array}{l}\text { High technical complexity } \\
\text { of portals }\end{array}$ & $\begin{array}{l}\text { Hahn and Wang (2009), Okujava and Remus (2007),Alavi and Leidner (1999), } \\
\text { Ginsberg and Kambil (1999), Mandviwalla et al. (1998), Jennex and Olfman (2002), } \\
\text { Barna (2003) }\end{array}$ \\
\hline 15 & $\begin{array}{l}\text { Weakness of portal } \\
\text { technology infrastructure }\end{array}$ & $\begin{array}{l}\text { Remus (2007), Alavi and Leidner (1999), Cross and Baird (2000), Davenport et al. } \\
\text { (1998), Ginsberg and Kambil (1999), Jennex and Olfman (2000), Mandviwalla et al. } \\
\text { (1998), Sage and Rose (1999), Yu, et al. (2004) }\end{array}$ \\
\hline 16 & $\begin{array}{l}\text { Lack of systems to } \\
\text { measure the effectiveness } \\
\text { of knowledge portal }\end{array}$ & $\begin{array}{l}\text { Alavi and Leidner (1999), Davenport et al. (1998), Jennex and Olfman (2000), Sage } \\
\text { and Rose (1999), Barna (2003) }\end{array}$ \\
\hline 17 & $\begin{array}{l}\text { Weakness in security and } \\
\text { protection of information } \\
\text { and knowledge }\end{array}$ & Jennex and Olfman (2000), Sage and Rose (1999) \\
\hline
\end{tabular}

Next section is devoted to an empirical investigation to determine the effects of these seventeen factors. 


\section{Research Methodology}

In order to determine the most important affecting issues on the implementation of KM in Iranian industries, a questionnaire was designed and distributed among two hundred related experts and then statistically analyzed. The sample targets were chosen from experts of Corporate Portal companies which most of their customers were involved with problems of knowledge management portals. In this survey 15.5 percent of respondents had $\mathrm{PhD}$ degree, 48.3 percent had postgraduate master degree and 36.2 percent had a bachelor degree. In our survey, 25.9 percent were staff employee, 27.6 percent were junior manager and 46.6 percent were director status. From the gender point of view, 32.8 percent were female and 67.8 percent of people were male. We used Likert Scale ordering numbers from 1 to 5 where 1 was representative for the lowest rate of importance and 5 was the greatest rate of importance. To determine the reliability of questionnaires, Cronbach's alpha method was used which was equal to 79.21 percent. We have also used Kolmogorov-Smirnov test to examine whether the data are normally distributed. This test helped us understand which parametric or nonparametric tests must be performed. The results of the test showed that we should apply non-parametric tests methods.

\section{Data Analysis}

\subsection{Friedman test}

The Friedman test in our survey is used to measure the priority index $\mathrm{K}$ of our $\mathrm{KM}$ affecting issues and the results have been summarized in Table 5. The third and forth columns of the Table indicate the mean rank and mean score of each item, respectively.

\section{Table5}

Friedman test result

\begin{tabular}{|c|c|c|c|}
\hline Row & Subject & Mean Rank & Mean Score \\
\hline 1 & Weakness in knowledge sharing culture & 12.15 & 4.4 \\
\hline 2 & Organizational strategy weakness & 11.33 & 4.28 \\
\hline 3 & Lack of senior manager's commitment and support & 11.28 & 4.24 \\
\hline 4 & Motivation weakness among portal's users and stakeholders & 10.34 & 4.07 \\
\hline 5 & Lack of flexibility and weakness in change management & 10.32 & 4.05 \\
\hline 6 & Information overcrowd and content management weakness & 10.09 & 4.07 \\
\hline 7 & Weakness in training & 10.05 & 3.98 \\
\hline 8 & Low technology acceptance among employees & 9.36 & 3.86 \\
\hline 9 & Lack of cohesion between portal and organization structure & 9.16 & 3.88 \\
\hline 10 & Weakness in security and protection of information and knowledge & 8.71 & 3.72 \\
\hline 11 & Lack of systems to measure the effectiveness of knowledge portal & 8.65 & 3.76 \\
\hline 12 & Portals project management weakness & 8.41 & 3.71 \\
\hline 13 & Weak acceptance of portal & 6.99 & 3.41 \\
\hline 14 & Financial and budget problems & 6.79 & 3.28 \\
\hline 15 & High technical complexity of portals & 6.58 & 3.31 \\
\hline 16 & Weakness of portal technology infrastructure & 6.54 & 3.31 \\
\hline 17 & Weaknesses in economic efficiency & 6.25 & 3.14 \\
\hline
\end{tabular}

As we can observe, the first item, weakness in knowledge sharing culture, rated as the highest factor and the last item, weaknesses in economic efficiency, has the lowest score in our survey. 
Table 6

Friedman Significant result

\begin{tabular}{llll}
\hline $\mathrm{N}$ & Chi-Square & Df & Asymp. Sig. \\
\hline 116 & 316.529 & 16 & 0 \\
\hline
\end{tabular}

Table 6 contains the main results of the test. As we can see, the Pearson Chi-square value with 16 degrees of freedom is zero and the significance test (P-Value) has zero value, which indicates that the zero assumption of the test is rejected.

\subsection{Correlation}

We have implemented the Spearman correlation coefficients test to verify the relationship among all parameters and the results have been shown in Table 7.

Table 7

Correlation analysis result

\begin{tabular}{|c|c|c|c|c|c|}
\hline Spearman's rho & Gender & Age & Education & Occupation & $\begin{array}{l}\text { Work } \\
\text { experience }\end{array}$ \\
\hline Organizational strategy weakness & 0.041 & 0.093 & 0.126 & 0.06 & 0 \\
\hline $\begin{array}{l}\text { Information overcrowd and content management } \\
\text { weakness }\end{array}$ & -0.043 & 0.055 & $.278(* *)$ & -0.077 & 0.104 \\
\hline Portals project management weakness & -0.062 & 0.038 & 0.046 & 0.02 & 0.131 \\
\hline Weakness in training & -0.154 & -0.139 & 0.151 & 0.049 & -0.14 \\
\hline Low technology acceptance among employees & 0.042 & 0.04 & 0.032 & 0.007 & -0.047 \\
\hline Financial and budget problems & -0.019 & -0.021 & -0.065 & -0.066 & $-.290(* *)$ \\
\hline Weak acceptance of portal & -0.025 & 0.024 & 0.154 & 0.083 & -0.105 \\
\hline $\begin{array}{l}\text { Motivation weakness among portal's users and } \\
\text { stakeholders }\end{array}$ & $-.217(*)$ & -0.04 & -0.074 & -0.16 & -0.078 \\
\hline $\begin{array}{l}\text { Lack of flexibility and weakness in change } \\
\text { management }\end{array}$ & -0.116 & 0.059 & 0.125 & -0.123 & 0.045 \\
\hline $\begin{array}{l}\text { Lack of cohesion between portal and organization } \\
\text { structure }\end{array}$ & -0.15 & 0.126 & $.198(*)$ & 0.141 & 0.085 \\
\hline Lack of senior manager's commitment and support & -0.091 & 0.02 & 0.153 & 0.04 & 0.166 \\
\hline Weakness in knowledge sharing culture & -0.047 & $.216(*)$ & 0.158 & $.202(*)$ & $.187(*)$ \\
\hline Weaknesses in economic efficiency & -0.012 & -0.075 & $-.224(*)$ & -0.069 & -0.089 \\
\hline High technical complexity of portals & $-.303(* *)$ & 0.034 & $.254(* *)$ & 0.04 & 0.004 \\
\hline Weakness of portal technology infrastructure & $-.287(* *)$ & $.224(*)$ & $.239(* *)$ & 0.127 & 0.037 \\
\hline $\begin{array}{l}\text { Lack of systems to measure the effectiveness of } \\
\text { knowledge portal }\end{array}$ & 0.088 & 0.131 & -0.036 & 0.162 & -0.034 \\
\hline $\begin{array}{l}\text { Weakness in security and protection of information } \\
\text { and knowledge }\end{array}$ & -0.086 & -0.072 & -0.161 & $-.202(*)$ & -0.132 \\
\hline $\begin{array}{l}{ }^{*} \text { Correlation is significant at the } 0.01 \text { level (2-tailed) } \\
\text { Correlation is significant at the } 0.05 \text { level (2-tailed) }\end{array}$ & & & & & \\
\hline
\end{tabular}


The results show that gender and the acceptance factor are negatively correlated. This means that women select the acceptance factor as a challenging factor in this survey. In addition, gender and the complexity factor are also negatively correlated which means that women distinguish complexity factor as a challenging factor more than men do.

On the other hand, gender and portal infrastructure show the same result which means that women also choose portal infrastructure factor as a challenging factor.

From the age point of view, the results show that age is correlated with knowledge sharing culture and portal infrastructure factors. It shows that older people consider them as the more challenging ones.

The results showed that Content Management factor is highly correlated with education which means that people with higher educational level choose content management factor as a more challenging factor. Similar results were hold for cohesion, capital, complexity and portal infrastructure.

In addition, job title and the knowledge sharing culture factor are correlated which means that higher ranks people choose this factor as a challenging one. On the other hand, the results show negative correlation of this variable with information security, which means that higher ranks don't consider this factor as a challenging one. Nevertheless, the analysis show that less experienced employees believe that budgeting is a challenge factor, while they don't consider the knowledge sharing culture factor as a challenge.

\subsection{Factor analysis}

Factor analysis discovers the latent variables of the research though it can be applied for data reduction as well. Table 8 shows the results for KMO and Bartlett tests as the preliminary phase of factor analysis. The results of these tests show that data are suitable for factor analysis.

Table 8

KMO and Bartlett's Test

Kaiser-Meyer-Olkin Measure of Sampling Adequacy. 0.522

\section{Bartlett's Test of Sphericity}

\section{Approx. Chi-Square}

Df

Sig.
569.024

136

Table 9 shows that the variables can be interpreted within six main factors with the coverage of about 67 percent. The results then were rotated with Varimax method and Table 10 summarizes the results of categorized seventeen items into six classified items.

\section{Discussion}

As we can observe from Table 5, some of the factors such as organizational strategy weakness, lack of senior manager's commitment and support are located on top of the raking. These items are mostly management related items. On the other hand, there are other financial items such as weaknesses in economic efficiency are listed on the bottom of our ranking system. Therefore, we can conclude that management plays a key role on knowledge management for Iranian firms. The other observation from the ranking system is that the average scores for all seventeen items are higher than the average ranking for all items together. This means that all these items are relatively important challenging factors regardless of their ranking. The correlation test results given in Table 7 indicates that the weak acceptance of portal, high technical complexity of portals and weakness of portal technology infrastructure are considered as the most challenging factors in women's opinion. 
Table 9

Total Variance Explained

\begin{tabular}{|c|c|c|c|c|c|c|c|c|c|}
\hline \multirow[b]{2}{*}{ Unit } & \multicolumn{3}{|c|}{ Initial Eigen values } & \multicolumn{3}{|c|}{$\begin{array}{l}\text { Extraction Sums of Squared } \\
\text { Loadings }\end{array}$} & \multicolumn{3}{|c|}{$\begin{array}{l}\text { Rotation Sums of Squared } \\
\text { Loadings }\end{array}$} \\
\hline & Total & $\begin{array}{l}\text { \% of } \\
\text { Variance }\end{array}$ & $\begin{array}{l}\text { Cumulative } \\
\%\end{array}$ & Total & $\begin{array}{l}\text { \% of } \\
\text { Variance }\end{array}$ & $\begin{array}{l}\text { Cumulative } \\
\%\end{array}$ & Total & $\begin{array}{l}\text { \%of } \\
\text { Variance }\end{array}$ & $\begin{array}{l}\text { Cumulative } \\
\%\end{array}$ \\
\hline 1 & 3.136 & 18.445 & 18.445 & 3.136 & 18.445 & 18.445 & 2.115 & 12.442 & 12.442 \\
\hline 2 & 2.17 & 12.767 & 31.212 & 2.17 & 12.767 & 31.212 & 2.005 & 11.797 & 24.239 \\
\hline 3 & 1.806 & 10.622 & 41.834 & 1.806 & 10.622 & 41.834 & 1.919 & 11.291 & 35.529 \\
\hline 4 & 1.548 & 9.104 & 50.938 & 1.548 & 9.104 & 50.938 & 1.911 & 11.238 & 46.768 \\
\hline 5 & 1.49 & 8.766 & 59.704 & 1.49 & 8.766 & 59.704 & 1.722 & 10.131 & 56.899 \\
\hline 6 & 1.18 & 6.942 & 66.646 & 1.18 & 6.942 & 66.646 & 1.657 & 9.747 & 66.646 \\
\hline 7 & 0.995 & 5.853 & 72.499 & & & & & & \\
\hline 8 & 0.88 & 5.174 & 77.673 & & & & & & \\
\hline 9 & 0.695 & 4.087 & 81.76 & & & & & & \\
\hline 10 & 0.62 & 3.65 & 85.41 & & & & & & \\
\hline 11 & 0.525 & 3.088 & 88.498 & & & & & & \\
\hline 12 & 0.479 & 2.816 & 91.314 & & & & & & \\
\hline 13 & 0.455 & 2.677 & 93.992 & & & & & & \\
\hline 14 & 0.357 & 2.099 & 96.091 & & & & & & \\
\hline 15 & 0.279 & 1.64 & 97.73 & & & & & & \\
\hline 16 & 0.215 & 1.263 & 98.993 & & & & & & \\
\hline 17 & 0.171 & 1.007 & 100 & & & & & & \\
\hline
\end{tabular}

The results of the factor analysis have also shown that we could categorize all items into six groups: Financial and information security, Technology and management, Senior management support and strategy, Acceptance, User's motivation and culture, Project management, Change management and training.

In our survey, it seems that older people with more experience believe that weakness of portal technology infrastructure and weakness in knowledge sharing culture would be most challenging issues. However, people with more educational background seem to address other issues as challenging factors such as information overcrowd and content management weakness, lack of cohesion between portal and organization structure, high technical complexity of portals, and weakness of portal technology infrastructure. 
Table10

Rotated Component Matrix (a)

\begin{tabular}{|c|c|c|c|c|c|c|}
\hline \multirow{2}{*}{ Subject } & \multicolumn{6}{|c|}{ Component } \\
\hline & 1 & 2 & 3 & 4 & 5 & 6 \\
\hline $\begin{array}{l}\text { Weakness in security and protection of } \\
\text { information and knowledge }\end{array}$ & 0.737 & -0.048 & 0.156 & 0.271 & -0.152 & -0.088 \\
\hline Financial and budget problems & 0.708 & 0.146 & 0.047 & 0 & 0.146 & 0.091 \\
\hline Weakness of portal technology infrastructure & 0.642 & -0.027 & -0.005 & 0.019 & 0.158 & 0.123 \\
\hline High technical complexity of portals & 0.102 & 0.835 & -0.068 & 0.212 & -0.011 & -0.201 \\
\hline $\begin{array}{l}\text { Lack of cohesion between portal and organization } \\
\text { structure }\end{array}$ & 0.008 & 0.727 & 0.37 & -0.058 & -0.085 & 0.344 \\
\hline $\begin{array}{l}\text { Information overcrowd and content management } \\
\text { weakness }\end{array}$ & 0.033 & 0.571 & 0.157 & -0.362 & 0.412 & 0.048 \\
\hline $\begin{array}{l}\text { Lack of systems to measure the effectiveness of } \\
\text { knowledge portal }\end{array}$ & 0.197 & 0.033 & 0.783 & -0.071 & 0.096 & 0.08 \\
\hline $\begin{array}{l}\text { Lack of senior manager's commitment and } \\
\text { support }\end{array}$ & -0.236 & 0.299 & 0.673 & 0.323 & 0.019 & -0.158 \\
\hline Organizational strategy weakness & 0.133 & 0.005 & 0.644 & -0.193 & 0.229 & 0.329 \\
\hline Low technology acceptance among employees & -0.006 & -0.095 & 0.012 & 0.861 & 0.073 & -0.023 \\
\hline Weak acceptance of portal & 0.313 & 0.221 & -0.051 & 0.669 & 0.146 & 0.198 \\
\hline $\begin{array}{l}\text { Motivation weakness among portal's users and } \\
\text { stakeholders }\end{array}$ & -0.098 & -0.174 & 0.351 & 0.262 & 0.752 & -0.046 \\
\hline Weakness in knowledge sharing culture & 0.253 & -0.077 & 0.01 & 0.295 & 0.656 & -0.349 \\
\hline Portals project management weakness & 0.15 & 0.256 & 0.031 & -0.104 & 0.534 & 0.174 \\
\hline $\begin{array}{l}\text { Lack of flexibility and weakness in change } \\
\text { management }\end{array}$ & 0.165 & 0.019 & 0.215 & 0.004 & -0.091 & 0.736 \\
\hline Weaknesses in economic efficiency & 0.546 & 0.309 & -0.026 & -0.15 & -0.001 & -0.576 \\
\hline Weakness in training & 0.122 & 0.289 & -0.269 & 0.365 & 0.311 & 0.507 \\
\hline \multicolumn{7}{|l|}{ Extraction Method: Principal Component Analysis. } \\
\hline \multicolumn{7}{|l|}{ Rotation Method: Varimax with Kaiser Normalization. } \\
\hline A Rotation converged in 22 iterations. & & & & & & \\
\hline
\end{tabular}

The next step in factor analysis is factor naming. In naming the factors, we should try to select the names in a way that the whole concept behind the factor, is clarified in the best way. The suggested titles for each factor are shown in Table 11.

The results of our analysis from the survey results of employees with higher authorities in different firms show that these people select weakness in security and protection of information and knowledge as low challenging factor and the weakness in sharing culture as more challenging factor. The survey results also indicate that information security is not an important challenge for organizations from their point of view. The survey results also show that, in terms of the job experience, weakness in knowledge sharing culture is selected as more important challenging item and financial and budget problems are considered as less important factor. This survey showed that job experience aspect is very similar to job position aspect. In our survey, it seems that people with more experience have almost the same opinion as the people with higher authority. In fact, these two groups of people are normally working together and they are the actual workers in a firm who are also familiar with the nature of the work. 
Table 11

Final test results from factor analysis

\begin{tabular}{|c|c|c|}
\hline Row & Classified Factor & Suggested Title \\
\hline 1 & $\begin{array}{l}\text { Weakness in security and protection of information and } \\
\text { knowledge, Financial and budget problems, Weakness of portal } \\
\text { technology infrastructure, Weaknesses in economic efficiency. }\end{array}$ & information \\
\hline 2 & $\begin{array}{l}\text { High technical complexity of portals, Lack of cohesion between } \\
\text { portal and organization structure, Mass information and portal } \\
\text { content, management Weaknesses. }\end{array}$ & Technology and management \\
\hline 3 & $\begin{array}{l}\text { Lack of systems to measure the effectiveness of Knowledge portal, } \\
\text { Lack of senior manager's commitment and support, } \\
\text { Organizational strategy weakness. }\end{array}$ & $\begin{array}{l}\text { Senior management support and } \\
\text { strategy }\end{array}$ \\
\hline 4 & $\begin{array}{l}\text { Low technology acceptance among employees, } \\
\text { Weak acceptance of portal. }\end{array}$ & Acceptance \\
\hline 5 & $\begin{array}{l}\text { Motivation weakness among portal's users and stakeholders, } \\
\text { Weakness in knowledge sharing culture, Portals project } \\
\text { management weakness. }\end{array}$ & $\begin{array}{l}\text { User's motivation and culture, } \\
\text { Project management }\end{array}$ \\
\hline 6 & $\begin{array}{l}\text { Lack of flexibility and weakness in change management, } \\
\text { Weakness in training. }\end{array}$ & management and \\
\hline
\end{tabular}

\section{Conclusion}

In this paper, we have performed an empirical analysis to determine the most important challenging factors for the implementation of knowledge management for Iranian industries. The results of this survey have shown that seventeen factors play key role on the success of any knowledge management project. These factors have been categorized into six groups and they are ranked using factor analysis. The survey has also emphasized that people with more experience and higher authorities believe that weakness in knowledge sharing culture could be one of the most important challenging factors while financial issues are less challenging factors. We hope the results of this study could be used for other developing countries who intend to adopt knowledge management for their corporations.

\section{Acknowledgment}

The authors are grateful for the constructive comments and suggestions of the anonymous referees on the earlier version of this work.

\section{References}

Ackerman, M. (1994). Definitional and Contextual Issues in Organizational and Group Memories, Proceedings of the $27^{\text {th }}$ Annual Hawaii International Conference on System Sciences, IEEE Computer Society Press, 191-200.

Ackerman, M. and Mandel, E. (1996), Memory In the Small: An Application to Provide Task-Based Organizational Memory for a Scientific Community. Proceedings of the Twenty-Ninth Annual Hawaii International Conference on System Sciences, IEEE Computer Society Press, 323-332.

Akhavan, Peyman, Jafari, Mostafa, and Mohammad Fathian (2006), Critical Success Factors of Knowledge Management Systems: a Multi-Case Analysis, European Business Review Journal, 18(2), 97-113. 
Alavi, M. and Leidner, D.E. (1999), Knowledge Management Systems: Emerging Views and Practices from the Field, Proceedings of the $32^{\text {nd }}$ Hawaii International Conference on System Sciences, IEEE Computer Society.

Barna, Z. (2003) Knowledge management: A critical e-business strategic factor. Unpublished master`s thesis, San Diego State University, San Diego.

Bergeron, B. (2003), Essentials of Knowledge Management, John Wiley \& Sons, Hoboken, NJ.

Blackmore, P. (1997), The development of an intranet within a college of further and higher education, ASLIB Proceedings, 49(3), $67-72$.

Carvalho, R., Ferreira, M. (2001), Using information technology to support knowledge conversion processes, Information Research, 7(1).

Cross, R. and Baird, L. (2000), Technology Is Not Enough: Improving Performance by Building Organizational Memory. Sloan Management Review, 41(3), 41-54.

Davenport, T. H., Delong, D. W \& Beers, M.C. (1998), Successful knowledge management projects, Sloan Management Review, 39(2), 43-57.

Encyclopedia of management $4^{\text {th }}$ Edition 1999, Marilyn M. Helms, D.B.A and Foreword by David A. Whetten, Thomson Gale publication.

Firestone, J. (2003), Enterprise Information Portals and Knowledge Management, KMCI Press/ButterworthHeinemann, Burlington, MA.

Ginsburg, M, Kambil, A (1999), "Annotate: a Web-based knowledge management support system for document collections", Proceedings of the $32^{\text {nd }}$ Hawaii International Conference on System Sciences, Maui, HI, 1-10.

Hahn, J. Wang, T. (2009), Knowledge management systems and organizational knowledge processing challenges: A field experiment, Decision Support Systems, 47(4), 332-342.

Holsapple, C. W., and Joshi, K.D. (2000), An Investigation of Factors that Influence the Management of Knowledge in Organizations, Journal of Strategic Information Systems, 9, 235-261.

Jafari, Mostafa and Peyman Akhavan (2007), Essential Changes for Knowledge Management Establishment in a Country: a Macro Perspective, European Business Review Journal, 19(1), 89-110.

Jafari, Mostafa, Akhavan, Peyman, and Elham Nouraniour (2009), Developing an architecture model for enterprise knowledge, an empirical study based on the Zachman framework in Iran, Management Decision, 47(5) 730-759.

Jafari, Mostafa, Akhavan, Peyman, Fesharaki, Mehdi, and Mohammad Fathian (2007), Iran aerospace industries' KM approach based on a comparative study: a benchmarking on successful practices, Aircraft Engineering and Aerospace Technology: An International Journal, 79(1), 69-78.

Jain, P. (2009), Knowledge management in e-government, Journal of Knowledge Management Practice, 10(4).

Jennex, M.E. and Olfman, L. (2000), Development Recommendations for Knowledge Management/ Organizational Memory Systems, Information Systems Development Conference.

Jennex, M.E. and Olfman, L. (2002), Organizational Memory/Knowledge Effects on Productivity, A Longitudinal Study, Proceedings of the $35^{\text {th }}$ Hawaii International Conference on System Sciences, HICSS35, IEEE Computer Society.

Jennex, M.E., Olfman, L. and Addo, T.B.A. (2003), The Need for an Organizational Knowledge Management Strategy, Proceedings of the $36^{\text {th }}$ Hawaii International Conference on System Sciences, HICSS36, IEEE Computer Society.

Jennex, M.E (2007), Knowledge Management Critical Success Factors, Encyclopedia of Portal Technologies and Application, Information Science Reference, 429-435.

Kim, G. (2003), Ten steps to intranet success, Online, 27(1), pp.66-9.

Koskinen, K.U. (2001), Tacit Knowledge as a Promoter of Success in Technology Firms. $34^{\text {th }}$ Hawaii International Conference on System Sciences, IEEE Computer Society.

Landqvist. \& Stenmark, D., (2007), Challenges and Pitfalls in portal information Management, Encyclopedia of Portal Technologies and Application, Information Science Reference, 118-122.

Malhotra, Y. and Galletta, D. (2003), Role of Commitment and Motivation as Antecedents of Knowledge Management Systems Implementation, Proceedings of the $36^{\text {th }}$ Hawaii International Conference on System Sciences, IEEE Computer Society.

Mandviwalla, M., Eulgem, S., Mould, C., and Rao, S.V. (1998). Organizational Memory Systems Design. Unpublished Working Paper for the Task Force on Organizational Memory, Burstein, F., Huber, G., Mandviwalla, M., Morrison, J., and Olfman, L. (eds.) Presented at the $31^{\text {st }}$ Annual Hawaii International Conference on System Sciences. 
Mphidi, H., Snyman, R. (2004), "The utilization of an intranet as a knowledge management tool in academic libraries", The Electronic Library, 22(5), 393-400.

Nonaka, I. and H. Takeuchi (1995), The knowledge-creating company. New York, Oxford University Press.

Okujava, Sh. \& Remus, U. (2007), Economical aspect when deploying enterprise portal, Encyclopedia of Portal Technologies and Applications, Information Science Reference, 282-288.

Remus, U. (2007), Success factors for the implementation of enterprise portal, Encyclopedia of Portal Technologies and Application, Information Science Reference, 985-991.

Sage, A.P. and Rouse, W.B. (1999), Information Systems Frontiers in Knowledge Management. Information Systems Frontiers, 1(3), 205-219.

Thompson, R.L., Higgins, C.A., and Howell, J.M. (1991), Personal Computing: Toward a Conceptual Model of Utilization, MIS Quarterly, 15(1), 125-143.

Uden, L. \& Naaranoja, M. (2007), Portals for knowledge management, Encyclopedia of Portal Technologies and Application, Information Science Reference, 795-799.

Vaccaro, Antonio (2009), The impact of virtual technologies on knowledge-based process: An empirical study, Research Policy, 38, 1278-1287.

Yu, S-H, Kim, Y-G, and Kim, M-Y, (2004), Linking Organizational Knowledge Management Drivers to Knowledge Management Performance: An Exploratory Study. $37^{\text {th }}$ Hawaii International Conference on System Sciences, HICSS36, IEEE Computer Society. 